\title{
CD19 Negative
}

National Cancer Institute

\section{Source}

National Cancer Institute. CD19 Negative. NCI Thesaurus. Code C132245.

Indicates that expression of CD19 has not been detected in a sample. 